\title{
DOS DATOS NUEVOS PARA LA HISTORIA DE LA IMPRENTA EN MÉXICO EN EL SIGLO XVI
}

Los orígenes y evolución de la imprenta en la capital de la Nueva España, desde sus comienzos en 1539 hasta el año de 1821 , han sido objeto de fundamentales trabajos de diversos bibliógrafos e historiadores, entre los cuales sobresalen por su importancia cuatro nombres: los de Joaquín García Icazbalceta (1825-1894), Vicente de P. Andrade (1844-1915), Nicolás León (1859-1929) y José Toribio Medina (1852-1930).

La obra más importante del primero ${ }^{1}$, en relación con el tema que nos ocupa, es la Bibliografía mexicana del siglo xvi, que vió la luz en 1886 , y que por la diligencia que en ella campea en la búsqueda de las noticias, la maestría con que éstas aparecen agrupadas y el estilo de buena cepa de que su ilustre autor hizo gala, marca una época en los anales bibliográficos del país ${ }^{2}$.

Continuando la historia tipográfica de México a partir del momento en que García Icazbalceta la había dejado, trabajó Andrade su Ensayo bibliográfico mexicano del siglo xvii, publicado en $1899^{3}$. El doctor León, meritísimo polígrafo, autor de una copiosa producción científica y literaria ${ }^{4}$ y amigo de García Icazbalceta, quien sostuvo con él y con otros eruditos una interesantísima correspondencia $^{5}$, no sólo adicionó la citada Bibliografía mexicana del siglo

1 Cf. Robert Ricard, "Joaquín García Icazbalceta, 1825-1894", en BHi, XXXVI, 1934; Manuel Guillermo Martínez, Don Joaquin García Icazbalceta: his place in Mexican historiography, Washington, 1947 (hay traducción con notas y apéndices por Luis García Pimentel y Agüero, México, 1950), y Natalicio González, “Icazbalceta y su obra”, en HistM, III, 1953-54, págs. 367-39o.

${ }^{2}$ Cf. Ricard, art. cit., págs. 4-5: "On peut travailler longtemps et minutieusement sur les livres, les introductions, les notices, les commentaires d'Icazbalceta sans le trouver un instant en défaut. Avec cela, il écrit sans emphase et sans affectation, d'un beau style simple, robuste et nourri d'érudit loyal, qui ne cherche qu'à dire tout droit ce qu'il veut dire, et qui emprunte parfois aux vieux auteurs du $x^{2}{ }^{e}$ siècle, ses familiers de tous les jours, un peu de leur fraîche et vigoureuse saveur".

s Cf. A. Millares Carlo y J. I. Mantecón, Ensayo de una bibliografia de bibliografias mexicanas, México, 1943, núm. 809, págs. 91-92.

4 Cf. ibid., núms. 638-644, págs. 75-76.

- Cartas de Joaquin Garcia Icazbalceta a José Fernando Ramirez, José Maria Ágreda, Manuel Orozco y Berra, Nicolás León, Agustin Fisher, Aquiles Gerste, 
$x v i^{6}$, sino que consagró sus desvelos a la compilación de lo referente a la centuria décimooctava, que salió a luz al público entre los años de 1902 y $1908^{7}$.

Basándose en todos estos trabajos, adicionándolos con nuevos hallazgos y completándolos, sobre todo en su aspecto documental, con prolijas investigaciones en diversos archivos, como el de Notarías del Distrito Federal, el General de la Nación (México) y el inagotable General de Indias (Sevilla), José Toribio Medina dió a conocer entre 1907 y 1912 los ocho volúmenes de su obra monumental La imprenta en México (1539-182I), salida de los propios talleres tipográficos del autor ${ }^{8}$.

Todos los países del mundo culto han celebrado en el transcurso del año $195^{2}$ el primer centenario del nacimiento de Medina ${ }^{9}$, cuya vida y escritos fueron objeto hace años de una hermosa monografía de Sara Elisabeth Roberts ${ }^{10}$. Fué este insigne erudito un investigador infatigable, que con la mira de estudiar e inventariar la producción de las imprentas americanas desde México hasta el Río de la Plata, no desperdició las oportunidades que su inteligencia, sus viajes y su desahogada posición económica le brindaban para llevar a feliz término sus propósitos. Los trabajos bibliográficos de Medina se sujetan, en líneas generales, a idéntico plan; en eruditas introducciones se investigan los orígenes del arte de imprimir en cada una de las ciudades o países estudiados, se insertan las biografías de los

Francisco del Paso y Troncoso, compiladas y anotadas por Felipe Teixidor, pról. de Genaro Estrada, México, 1937.

- Millares y Mantecón, op. cit., núms. 804-807, pág. 91.

- Ibid., núm. 810, págs. 92-93.

8 Ibid., núm. 1201 , pág. 133.

' La creación en Chile del Fondo Histórico y Bibliográfico que lleva su nombre y que se propone reeditar las obras conocidas del insigne investigador, dar a conocer las inéditas y publicar trabajos relacionados con los temas cultivados por el autor de la Biblioteca hispanoamericana, constituye un acierto merecedor del mayor y más sincero encomio. Los aborigenes de Chile (con introducción de Carlos Keller R.), la Historia del tribunal del Santo Oficio de la Inquisición en Chile (prólogo de Aniceto Almeyda), Cosas de la colonia. Apuntes para la crónica del siglo xviii en Chile (introducción de Eugenio Pereira Salas), Las matematicas en la Universidad de San Felipe, Tres estudios históricos, Una excursión a Tarapacá y el Ensayo biobibliográfico sobre Hernán Cortés, Obra póstuma (introducción de Guillermo Feliú Cruz) son las publicaciones del Fondo de que tenemos noticia. El Ejército y la Armada de Chile se han sumado respectivamente a este homenaje con la reedición de las obras de Medina tituladas Ensayo acerca de una mapoteca chilena (introducción de Elías Almeyda Arroyo) y El capitán de fragata Arturo Prat. El vicealmirante Patricio Lynch (estudio y prólogo de Roberto Hernández C.). En diversas revistas se han publicado artículos de importancia que habrá que tener en cuenta cuando se escriba el estudio de conjunto sobre Medina, que aún se echa de menos.

${ }^{10}$ José Toribio Medina. His life and works, Washington, D. C., 1941 (Interamerican Bibliographical and Literary Association, Series I, vol. 6). 
impresores, con noticias en muchos. casos inéditas o poco conocidas, se valora críticamente la aportación de los bibliógrafos anteriores (Eguiara y Eguren ${ }^{11}$, Beristáin y Souza ${ }^{12}$, Osores ${ }^{13}$, etc., en el caso de México), se enumeran cronológicamente las obras, con transcripción de sus portadas y colofones, descripción interna y externa, relación de los ejemplares conocidos y de las obras bibliográficas en que anteriormente se los había estudiado, y se ofrecen notas biográficas y documentales acerca de sus autores ${ }^{14}$. Todo ello contribuye a que las publicaciones de Medina, que ilustran la producción de las prensas de Chile, Perú, Guatemala, Buenos Aires, etc. durante el período colonial, constituyan una inestimable contribución a la historia cultural, en sus diversos aspectos, de los mencionados países.

Por lo que se refiere a la imprenta en México, la obra antes citada del autor que nos ocupa ofrece, todavía hoy, la más completa visión de conjunto; pero es evidente que, desde la fecha de su publicación acá, han sido varios los hallazgos de libros, folletos y hojas sueltas de que Medina no alcanzó a tener noticia, y que exigen ser debidamente registrados y descritos, mientras llega el momento de fundirlos a la obra original en una nueva edición.

Señalemos, a este propósito, los dos notables volúmenes publicados por el bibliógrafo mexicano Francisco González de Cossío, uno en 1947 , y otro en $195^{2^{15}}$, que se refieren a la totalidad del período abarcado por el erudito chileno en su obra sobre la producción tipográfica en la capital de la Nueva España.

Mayor interés han despertado las noticias concernientes al siglo xvi, primero del funcionamiento de la imprenta mexicana. Los trabajos de Nicolás León, antes aludidos, y los más recientes del doctor

11 Millares y Mantecón, op. cit., núm. 458, págs. $5^{6-5} 5^{8 .-A d e m a ́ s ~ d e ~ l a ~ n o t i-~}$ cia concerniente a Sor Juana Inés de la Cruz, que se publicó en 1936 con una advertencia y prólogo de Ermilo Abreu Gómez (vol. II de la Biblioteca histórica mexicana de obras inéditas), han visto la luz otras dos de las incluídas en la parte inédita de la obra de Eguiara (letras $C-J$, Biblioteca de la Universidad de Texas, en Austin, y fotocopia en la de la Secretaría de Hacienda de México), a saber: la del humanista Francisco Cervantes de Salazar, en Cartas recibidas de España por Francisco Cervantes de Salazar (1560-1575), introd., notas y apéndices de A. Millares Carlo, México, 1946 (Biblioteca histórica mexicana de obras inéditas, vol. XX), apénd. III, págs. 181-189, y la de Juan Ruiz de Alarcón: A. Mrllares Carlo, "Eguiara y Ruiz de Alarcón", en HistM, I, 1951-52, págs. 616-620.

12 Millares y Mantecón, op. cit., núms. 449-452, págs. 54-56. Añádase la nueva edición publicada en México (Ediciones Frente Cultural), 1947, 5 vols.

${ }^{13}$ Ibid., núm. 812, pág. 93.

${ }^{14}$ Cf. Jorge Zamudio Z., "Medina y la bibliografía”, en $A$, CVII, 1952, páginas $4^{21-514}$, sobre todo págs. $5^{09-513}$.

${ }^{15}$ La imprenta en México, 1594-1820. Cien adiciones a la obra de don José Toribio Medina, pról. de A. Millares Carlo, México, 1947; La imprenta en México (1553-1820). 510 adiciones a la obra de José Toribio Medina, en homenaje al primer centenario de su nacimiento, México, $195^{2}$. 
Emilio Valton ${ }^{16}$, del propio González de Cossío ${ }^{17}$, de Henry R. Wagner ${ }^{18}$ y algunos más ${ }^{19}$, han aumentado considerablemente el número de las obras producidas en México durante esa centuria, y han hecho pensar en la conveniencia de preparar una segunda edición de la Bibliografia mexicana del siglo xvi, de García Icazbalceta, que, adicionada y anotada por el autor de estas líneas, publicará en breve el Fondo de Cultura Económica, de México.

Al tiempo de redactar nuestros complementos a la obra que acabamos de mencionar, desconocíamos la existencia de dos libros que se suponen impresos en la Nueva España y en la centuria décimosexta. El primero, que no hemos logrado examinar, constituiría una novedad sensacional, ya que su poseedor, el librero y bibliógrafo madrileño don Francisco Vindel, afirma haber sido impreso en Tlaxcala por un naipero, hacia 1534; sólo que en comprobación

${ }^{16}$ Impresos mexicanos del siglo xvi. (Incunables americanos). Estudio bibliográfico con una introducción sobre los origenes de la imprenta en América, México, 1935; "Algunas particularidades tipográficas de los impresos mexicanos del siglo xvi", en Asociación de Libreros de México. IV Centenario de la impren. ta en México, la primera de América, México, 1940, págs. 239-277; El primer libro de alfabetización en América. Cartilla para enseñar a leer, impresa por Pedro Ocharte en México, 1569. Estudio critico, bibliográfico e histórico, México, 1947, y "El arte tipográfico de Antonio de Espinosa y Pedro Ocharte. Estudio crítico", en Manuel Porrúa, Catálogo bibliográfico, advertencia prel. de A. Millares Carlo, México, 1948.

${ }^{17}$ En sus primeras Adiciones a Medina incluyó dos impresos (1594 y 1596) atribuídos a Balli, y en las segundas, trece del siglo XVI, conocidas por referencias seguras $(1553,1557,1559,1567,1568,1574,1578,1587$ [2], 1590, 1595, 1599 [2]).

${ }_{18}$ Nueva bibliografia mexicana del siglo xvi. Suplemento a las Bibliografías de don Joaquin Garcia Icazbalceta, don José Toribio Medina y don Nicolás León. Traducida por Joaquín García Pimentel y Federico Gómez de Orozco, México, 1946.

19 Manuel Porrúa, en el Catálogo bibliográfico antes citado, dió a conocer cuatro formularios para carta de poder (núms. 141, 143, 144 y 145, págs. 40-45) y uno de escritura de fianza (núm. 142, pág. 42), probables impresiones de Pedro Ocharte. Julián Calvo, a quien debemos la noticia del impreso desconocido de Balli, que luego se describe, y el autor de estas notas, publicaron recientemente una monografía sobre el prototipógrafo mexicano, en la que se formulan conclusiones nuevas sobre los tipos de imprenta usados por el mismo (Juan Pablos, primer impresor que a esta tierra vino, México, 1953). El erudito bibliófilo don Salvador Ugarte ha dado a conocer en reproducción facsímil la rarísima diserta. ción en elogio de la Jurisprudencia publicada en 1596 por Balli, "In officina parentis". La real provisión en que Felipe II ordena se adopte en la Nueva España la reforma del calendario promulgada por el papa Gregorio XIV fué impresa en México por Pedro Ocharte, y el único ejemplar conocido, no descrito hasta ahora, se conserva en una biblioteca particular. De la Relación del espantable terremoto que agora nuevamente ha acontecido en la ciudad de Guate. mala, etc., impresa en México, en casa de Juan Cromberger, no se conserva ningún ejemplar, pues todas las ediciones que en facsímil se han hecho de este texto y los ejemplares existentes del mismo -incluído el que recientemente se ha descubierto en la Biblioteca del Escorial- pertenecen a una edición espa- 
de tan extraños asertos no se aduce ningún argumento que pueda considerarse como prueba ${ }^{20}$.

Un ejemplar del segundo figuró en la reciente Exposición del Libro celebrada en Madrid en 1952. Se trata del Nuevo vergel de olorosas flores sembradas por la muerte dolorida y cogidas por la trabajada vida, obra de un Diego Bernal de las Indias, que ya había visto la luz en rarísima edición de Sevilla, Bartolomé Pérez, 1534 (B.N.M., sign. R-3973) y que, según el pie de imprenta del ejemplar que nos ocupa, salió de los talleres de Juan Pablos en 1546 . Pero los tipos góticos aquí usados no son los que empleaba el prototipógrafo mexicano ni antes ni después de $155^{\circ}$, y el opúsculo en cuestión nos parece una mistificación, aunque no se nos alcanza quién pudo hacerla ni los motivos que le guiaron ${ }^{21}$.

Veintiún documentos referentes a tipógrafos que ejercieron su oficio en México en el transcurso del siglo xvi citó o insertó García Icazbalceta en su Bibliografia. La nueva edición de esta obra incluirá ochenta, a los que habrá que añadir el siguiente inédito ${ }^{22}$.

Pedro Ocharte, ympressor.

$159^{2}$

Para que se pague la ympressión

y costo de dos mill mandamientos que se ym-

primieron tocantes a la cobran-

ça del seruicio de los quatro rreales.

\section{D X C II años}

Don Luis de Velasco, etc. A vos los juezes, officiales de la Real Hazienda de su Magestad en esta dicha Nueua Spaña. Bien sauéis que Pedro Ocharte, vezino desta çiudad de México, ympressor de libros, me hizo rrelación que por mi mandado auía ympresso dos mill mandamientos de a tres pliegos cada vno sobre los quatro rreales que an de dar los yndios, negros y mulatos libres de seruiçio para ayuda a los gastos que su Magestad tiene, y asimismo otros quinientos de a pliego, y de los de a tres pliegos tenía entregados

ñola, sin lugar ni año, que en su título, y después de las palabras "ha acontecido", añade "en las Indias, en una ciudad llamada Guatimala", palabras que se leen también en la edición publicada en Toledo, 1543, reproducida en facsímil en los Anales de la Sociedad de Geografia e Historia de Guatemala, XIII, marzo-junio de 1948.-Señalemos, por último, el importante artículo de C. Mirali.es de Imperial y Gómez, “Censura de publicaciones en Nueva España (1576-1591). Anotaciones documentales", en RevIndM, X, 1950, págs. 817-846, que incluye dos documentos (núms. 14-15, págs. 837-839) sobre el Diálogo de doctrina cristiana de fray Maturino Gilberti.

${ }^{20}$ El primer libro impreso en América fué para el rezo del Santo Rosario (Méjico, 1532-1534), ed. facsimilar con comentarios de Francisco Vindel, Madrid, 1953 .

${ }^{21}$ C.f. Exposición histórica del Libro. Un milenario del libro español. Guía del visitante, Madrid, 1952, núm. 816, pág. 141.

${ }^{22}$ Archivo Histórico de Hacienda (México), leg. 424-107, 1 fol. Debemos su conocimiento a don Luis Felipe Muro, de El Colegio de México. 


\section{VB I L E O PLEN IS I M O, QVEN VES tro muy S. Padre Gregorio.14. ha concedido a toda la Chriftian dad,para los Sanctos fines, que abaxo van declarados.}

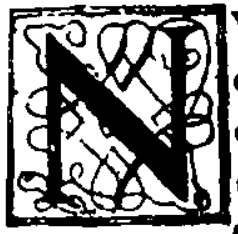

V E S T RO muy Sancto Padre Gregorio .xiiij.figuiendo el loable exemplo de muchos Romanos Pontifi ces,quealiprincypio de fu pontifica do acoftumbraró a pedir a D ios nueftro Señorfu efpiritu, y gracia, ycombi dazon a los fietes a Oracion, Penitenciza, y obras de mifericordia: para q́anfi rodos jútos, la cabeģa con los mié bros,mejor alcançafle de fu diuina Mageftad el fxuor y ayuda á para el goviérmo, y adminiftració de fu Iglefia

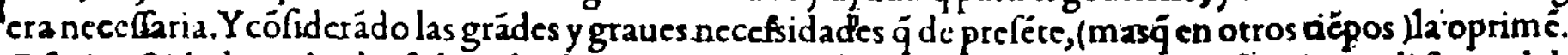

C ONCEDE fu Sanctidadia todos losferles Chriftianos,ä envna de tas dos emanas primeras figuientes dépues del Do-

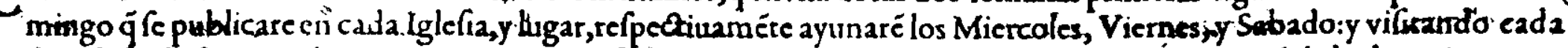

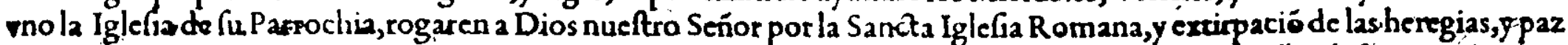

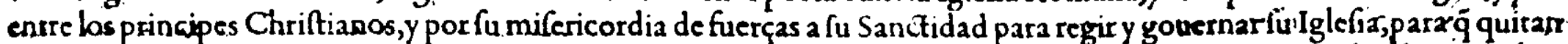
do los herrores della ceffen daños prefentes, ylos qupor nueftra culpa tenemos. Y a fsi inifmo dierertlimolna la qu les pareciere y en efte tiépo conferfaren fuspeccados, fiel Donigao otro dia de la femana figuiente,comulgaren, haziendo rodo lo fufo.

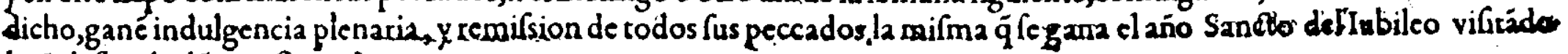
las Iglefias dedétro y fusra de Roma.

TEN que los que eftuuieren en Monafterios, ò en carceles, ó por enfermedad, ò otro ligitimo impedimento no pudieren hazer las obras fufo dichas.àalgunas dellas, pueda el confeffor commutarfelas en otras obras de piedadjàdiferirlo en otro ziempo,para luege que cerfen los tales impedimentos.

T E N que pueda elegir cófeffor, regular, ó fecular de los aprouados por el Ordinario, el qual por efta vez, los pueda en el fuero de la cóciencia abloluer imponiédoles penitencia conforme a la culpa de todas ò quales quierexcomuniones, furpen fiones, antredichos, y ouras qualefyuicr.céluras, fentencias, y penas Ecclefiafticas im pueftas por derecho ò por Inex; por qual quier:caufe áfean. Yafsi mifmoles pueda abfoluer de rodos los peccados, exceffos crimines, ydelitos porgraues è ynor mes Gf $f_{c} a n, y$ de los cafos referuados a los Ordinarios, s a la Sanctarfede Apoffolica,por qualefquier Romanos Pontificesyaun $\emptyset$ fean de tos contenidos en la Bulla in cana. Domini. Yno es el intento de fuSanctidad, que fe difpenfe deirregularidadiqual quiera qufezoculca opublica ni do qualquiera in habilidad qu de alguna manera fe ay a concrabido;.

IT E Nconcede, que pueda el confeffor conmutar todos y qualefquier votos, Ecepro el de Religion, y Caftidad; en otras obras pias

IT OD O lo fufo dicho concede fu Sanctidad en el fuero de la conciëcia tanfolamente, y ro aqüllos á eftubieren defcomul gados,entredichos de clarados, ò de nunciados por algú luez, lino fuere tan folamére para effecto deganar efte S.jubilco.

IT O D.O efto concedefu Sandidad fin embargo de qualeliguier. Cöftituciones. Apoftelicas po $\mathrm{I}$ las quales qualquier de los Romanos Ponxtifces fus predeceflores, ayan referuado en fila abfoluciō de algunos éa for particulares $q$ n novaliefie

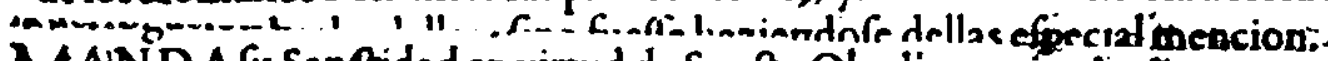

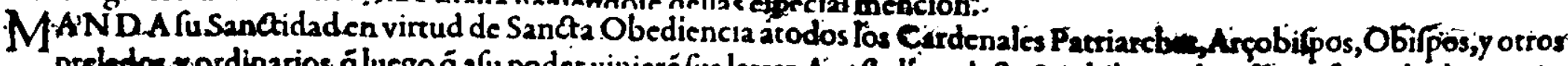

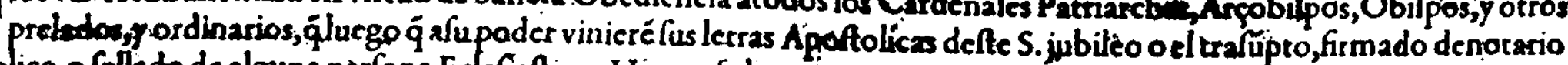
publico, $p$ follado de alguna perfona Eclefiaftica. Hagan folenesi rogatiuas, y proceffiones, el diz, y enla yglefia ò yglefias ğ les parefaken conuenir, y hagan publicar, efte S.jubileo por todias lasprovinacias y Yglefias de fus diocelsisy juridicion.

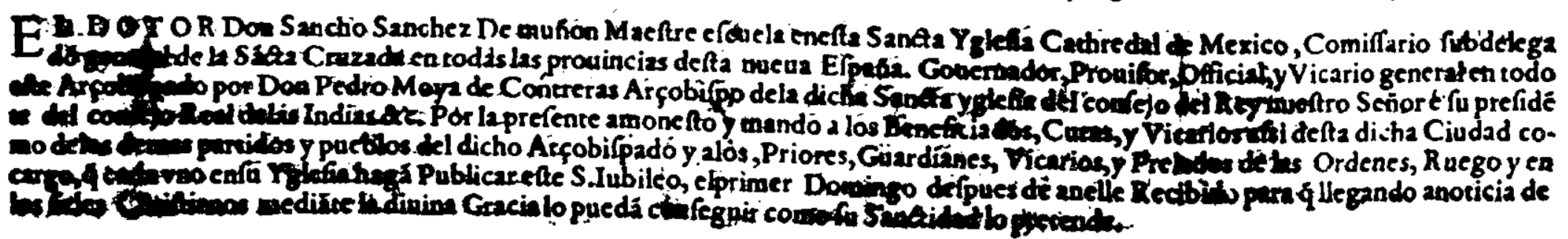

\section{EnM exico e ncafa de PedroBalliz sg 2}


a Augustín de Ribera mill y ochocientos, y de los de a pliego quinientos, como constaua de vna certificaçión de que hizo demostraçión, y que los doçientos rrestantes tenía entregados a Joan de Villaseca, mi secretario, y me pidió se le mandase pagar el trabajo y costo dellos; y por mí se os rremitió os conçertásedes con el dicho Pedro Ocharte y me ynformásedes lo que mereçía por esta ympresión y me hiziésedes rrelaçión de dónde se le podía pagar. En cumplimiento de lo qual la hizistes como os auíades conçertado con él, y pues le deuía pagar por la ympresión y papel de cada mandamiento de los de a tres pliegos treinta y quatro maravedís, y lo que montasse a este rrespecto se le pagase de lo que cayesse del seruicio que han de hazer los dichos yndios, negros y mulatos, y porque dél no auía caýdo en vuestro poder cosa alguna, se le podría pagar de la Real Caxa a qüenta de lo que se cobrase del dicho seruicio, y que por los mandamientos de a pliego estaua fecho el conçierto a onze maravedís cada vno, y la paga déstos fuese en otra cosa; y por mí visto, atento a lo susodicho, por el presente os mando que de qualquier maravedís o pesos de oro que son o fueren a vuestro cargo de los quatro rreales que an de contribuir los dichos yndios, negros o mulatos por bía de seruicio para su Magestad, libréis y paguéis al dicho Pedro Ocharte o a quien su poder ouiere lo que montaren la ympresión e costas de los dos mill mandamientos de a tres pliegos, que stan hechos en esta rrazón, a treinta y quatro maravedís cada vno, conforme al conçierto que con él hizistes, y en el entretanto que no reçiuís dinero tocante a el dicho seruicio, del que está o entrare en vuestro poder de la Real Hazienda los supláis y paguéis por aora, con cuidado de lo enterar después a la Real Caxa lo que fuere, con toda claridad, que lo que montare con este mandamiento e su carta de pago os será rreçiuido en qüenta. Y en lo que toca a la paga de los quinientos mandamientos de a pliego, ocurra el dicho Pedro Ocharte al depositario que está señalado para pagar a los secretarios de gouernaçión, cámara y otros officios, para que de los pesos de oro que entraren en su poder, de los que están mandados rrecoger de las comunidades de los pueblos desta Nueua Spaña, deste género, se lo libre y pague, conforme al dicho conçierto, a rrazón de onze maravedís cada pliego, que lo que fuere, con su carta de pago y treslado deste mandamiento autorizado del escriuano, estarán bien dados. Fecho en México, a diez de jullio de mill y quinientos y nouenta e dos años.-Don Luis de Velasco. Por mandado del virrey, Pedro de Campos.

Gerónimo López, thessorero de la Real Hazienda desta Nueua Spaña, de los maravedís y pesos de oro que della son a vuestro cargo, a qüenta de lo que proçediere de los quatro rreales de seruiçio que están mandados pagar para su Magestad a todos los yndios desta Nueua Spaña y a los negros y mulatos libres della para socorro de sus neçesidades y gastos, dad y pagad a Pedro Ocharte, ympressor de libros desta çiudad o a quien su poder ouiere, doçientos y çinqüenta pesos de oro comund, que 
a de auer y se le deuen y mandan librar y pagar por mandamiento del virrey don Luis de Velasco fecho diez deste presente mes y año, por la ympresión y costa de dos mill mandamientos que se hizieron de molde, de a tres pliegos de papel cada vno, sobre el orden que a de tener en la paga del dicho seruiçio, a rrazón de treinta y quatro maravedís cada mandamiento, que es el precio a como por nosotros fueron tassados por mandado del dicho virrey, como en el dicho mandamiento se declara, con el qual y los entregados desta otra parte y este libramiento y su carta de pago se os rreçiuirán en qüenta. Fecho en México, a veinte y ocho de jullio de mill y quinientos y nouenta y dos años.

Al mismo año de 1592 , fecha del documento transcrito, pertenece el siguiente impreso de Pedro Balli, que ahora se describe por vez primera $^{23}$ :

IVBILEQ PLENISSIMO, QVE NVES $\mid$ tro muy S. Padre Gregorio .14. ha concedido a toda la Christian||dad, para los Sanctos fines, que abaxo van declarados. || (Sigue el texto, y al fin:) || En Mexico en casa de Pedro Balli $159^{2}$.

Una hoja en doble folio, impresa por una sola cara, en letra romana, con hermosa $N$ capitular iniciando el texto (véase la reproducción).

Se trata del jubjeo de estilo concedido por Gregorio XIV al inaugurar su breve pontificado. Lo mandó publicar el doctor don Sancho Sánchez de Muñón, maestrescuela de la Iglesia Catedral de México, comisario subdelegado general de la Santa Cruzada en las provincias de la Nueva España, gobernador, provisor, oficial y vicario general en el arzobispado de México por el arzobispo don Pedro Moya de Contreras.

Como fueron tan breves los pontificados de Gregorio XIV ( 5 de diciembre de 1590 a 15 de octubre de 1591 ) y de su sucesor Inocencio IX (29 de octubre a 30 de diciembre de 1591), resulta que el jubileo de que tratamos se publicó en la Nueva España siendo ya papa Clemente VIII.

Agustín Millares Carlo

El Colegio de México.

${ }^{23}$ Biblioteca Pública del Estado de Jalisco (Guadalajara, México), Colección de Documentos, tomo 34, vol. 3, hacia el fol. 40.-Museo Nacional de Historia (México, D. F.), Archivo de microfilms, serie Guadalajara, rollo 22. 